\title{
This Is Not a Game: Violent Video Games, Sacred Space, and Ritual
}

\author{
Rachel Wagner
}

Some things have to be believed to be seen.

-Ralph Hodgson

Video games, especially those with religious content, create something similar to sacred space. They can, like sacred spaces, provide a sense of orientation via the assumption of an ordered cosmos with predictable rules. They too can frame discrete spatial elements, and sometimes even attempt to map the rules of the circumscribed space onto reality. They focus desire by presenting us with a symbolic arena in which designers have predetermined how things should work. In those video games that intersect directly with religion via symbolism or depiction of real sacred space, the game itself also often functions as a sort of sacred space, with many of the same features and symbolic, ideological functions. If the deliberate circumscribing of space is a means by which humans map order onto reality, then looking at video games as having ritual and spatial components seems an apt means of uncovering their ideological potential.

In the middle of the twentieth century, long before video games were even imagined as a mode of popular entertainment, religious theorist Mircea Eliade argued that the recognition of the "sacred" within the "profane" world is a kind of order-making activity, offering a "hierophany" that reveals "an absolute fixed point, a center" within otherwise chaotic space (21). For Eliade, "to organize a space is to 
repeat the paradigmatic work of the gods” (32). The creation and maintenance of sacred space is a way of rejecting the chaos of ordinary life, of symbolically arguing instead for an ordered cosmos, represented symbolically by the ordered area of the sacred space itself, set apart from the rest of life. Much more recently, media theorist Ken Hillis has expressed a similar sentiment about virtual reality's ability to induce our sense of desire, transcendence, and the ideal. Hillis notes an idealization of virtual reality, marked by "a widespread belief that space (understood variously as distance, extension, or orientation) constitutes something elemental.” Virtual reality lulls us into thinking that the space behind the screen is real, since it "reflects support for a belief that because light illuminates space it may therefore produce space a priori." The illusion of space registers for us as real space. As a result, says Hillis, users of virtual reality "may experience desire or even something akin to a moral imperative to enter into virtuality where space and light ...have become one immaterial "wherein." We are motivated by the desire for a "sense of entry into the image" and encouraged to view the screen and its mechanisms as a "transcendence machine" or "subjectivity enhancer," that "works to collapse distinctions between the conceptions built into virtual environments by their developers and the perceptive faculties of users" ("Modes of Digital Identification” 349). That is, the technology encourages us to see virtual reality as more "real" than reality.

Brenda Brasher similarly observes in cyberspace what she calls "omnitemporality," that is, "the religious idea of eternity as perpetual persistence" (52). Although the notion of "omnitemporality" first manifested as a religious notion, the “concrete expression or materialization of the monks' concept of eternity," it finds new expression today in wired culture. Cyberspace, like the religious notion of the infinite, "is always present." It mimics much older ideas about heaven, since "whatever exists within [cyberspace] never decays. Whatever is expressed in [it] ... is perpetually expressed ... the quasi-mystical appeal that cyberspace exudes stems from this taste of eternity that it imparts to those who interact with it” (52). Virtual reality proposes a means of crossing beyond the vicissitudes of ordinary life into an "immaterial 'wherein"” of imagined permanence and the fulfillment of dreams. Virtual reality promises, at times, to work as a kind of sacred space itself. ${ }^{1}$ Hillis and Brasher are speaking of virtual reality in its most general sense, as a sort of imagined ideal space behind the screen. But the notion of a space that is set apart for symbolic activities applies even more powerfully to the study of video games, which are set apart not only by the screen but also by the activities that take place within that screen. In this way, video games mark themselves as "scripted" experiences that share some important features with the "scripted" experience of ritual, both of which take place in circumscribed spaces set apart from ordinary life.

Traditional theorists of sacred space emphasize the importance both of the place in which sacred symbolic activity occurs and the kind of symbolic activity that happens there. Ritual and sacred spaces, then, are closely related theoretical concepts. By considering the many ways that sacred space and video games overlap as symbolic spaces of ritualized order-making, this discussion will open the way to consider what happens when games work as sacred spaces, urging a kind of worldview-shaping perspective that can function in powerful and sometimes 
disturbing ways. This comparison offers surprising new insights about how humans act in circumscribed spaces - whether they are explicitly religious or not—and how they use these circumscribed spaces to map order onto reality itself.

The method here is cumulative. By introducing key concepts that build upon one another, I move from the theoretical into the practical, weaving together key notions from theory about ritual, about sacred space, and about gaming. Ultimately, I show how violent war-based video games, when they work like rituals and like sacred spaces, have the potential to map onto real life as dangerous models for how to interact with others. Indeed, if video games can work as sacred spaces, then we should be particularly critical of those games that use this power to foment divisive usversus-them modalities. After introducing the key theoretical concepts that will help to make sense of the phenomenon, I present several troubling case studies of what can happen when violent gaming worlds map onto reality. I end with a case study about an Iranian Muslim game designer who fell victim to the simplified ritualized dualisms inherent in the American video games he himself designed and who was subsequently sentenced to death.

\section{Sacred Space}

Sacred space is "significant space, a site, orientation, or set of relations subject to interpretation because it focuses crucial questions about what it means to be a human being in a meaningful world" (Chidester and Linenthal 12). Human beings build sacred places and engage in sacred ritual as a way of projecting or enacting their own desire for meaning, their own hope that there is indeed a "Sacred" or a "Real" beyond worldly, profane existence. Similarly, people construct video games as a kind of sacred space into which they inject their wishes for how the world might work. Video game construction, like ritual performance, is a means of demonstrating desire, of mapping order, of developing rules for how to live. People who build sacred spaces are often making the claim, through their actions, that there is a sacred model, a Real, that should be copied in this world. Video games can, at times, exhibit similar features of order-making.

Contemporary theorists of sacred space argue that such spaces need not exhibit a "timeless" quality of the sort proposed by Eliade, but can be identified more readily by their functional qualities, their ability to circumscribe space in deeply meaningful and often ideologically determined, ways. Roger Friedland and Richard D. Hecht point out the limitations of the work of classic theorists like Eliade, Gerardus van der Leeuw, and Joachim Wach who identify sacred spaces as "sacred for all time" without enough attention paid to "how space is socially constructed, organized, and reproduced over time." With such an approach, they explain, sacred space is "stripped of politics and real history" (25). Instead, they propose, sacred space is "more a matter of interpretation, of setting boundaries, and of relationships than fixed categories which have universal consent and agreement among and between believers" (27). Chidester and Linenthal agree, arguing that sacred space is ritual space, a "location for formulized repeatable symbolic performances"-a description that sounds a lot like the arena of a video game, in which experiences are typically 
highly scripted and shaped, repeatable until the player gets it "right" in terms of the game’s predetermined design for performance (9).

Drawing on the work of Dutch cultural theorist Johan Huizinga, an argument can be made that ritual, sacred space, and play have a lot in common in that all of these create a distinct space separate from everyday life for special activities. As Huizinga explains, "we find play present everywhere as a well-defined quality of action which is different from 'ordinary' life" (4). Play, he says, is a "stepping out of 'real' life into a temporary sphere of activity with a disposition all of its own” (8). Play provides a space and time in which new rules adhere, in which one can perform "an act apart." Play, says Huizinga, “creates order, is order” such that "into an imperfect world and into the confusion of life it brings a temporary, limited perfection" via the establishment of fixed rules and outcomes (10). Ritual enacts a similar mode of cosmos crafting. Ritual performers "are convinced that the action actualizes and effects a definite beatification, brings about an order of things higher than that in which they customarily live” (14). In this sense, we need not determine whether or not Eliade or Huizinga are right to posit a Platonic "Real" or "Sacred" to which all "sacred space" gestures. Rather, it is enough to observe the human wish that sacred spaces should point beyond themselves to something more "real" and to observe the ritualized activities they perform to convince themselves that they do.

Friedland and Hecht are critical of what they see as Eliade's oversimplification of the contested nature of sacred locations, but they do agree with him that sacred space is a potent site for human meaning-making. Emphasizing the political and interpretive elements of sacred space construction and use, they argue that sacred space must be viewed as "a structure of limitation and closure, like the canon or the process of divination with a fixed and limited number of objects to be interpreted and understood." Sacred space is more a conversation than a thing; it is "a matter of context and relation with specific grammars which make them meaningful," shaped by "grammars which regulate" our understanding of the space itself (27). This notion of space as a negotiated site of meaning marks the ability of sacred space to function in ways that emphasize the give and take of meaning as interplay with rules. That is to say, sacred space can function as a form of play, a notion that itself is integrally related to ritual. Put in Huizinga's terms, sacred space, like ritual and play, is a kind of "magic circle." Indeed, the "magic circle" turns out to be a key principle in the comparison between the paired theoretical components of ritual/sacred space and program/virtual space.

\section{The Magic Circle}

For Huizinga, play “proceeds within its own boundaries of time and space according to fixed rules and in an orderly manner. It promotes the formation of social groupings which tend to surround themselves with secrecy and to stress their difference from the common world by disguise or other means” (13). Huizinga recognizes the similarities between games and rituals when he observes that in a sacred ritual performance, the participants are also engaged in a kind of sacred play that "brings about an order of things higher than that in which [participants] custom- 
arily live.” The ritual performance, however, “still retains the formal characteristics of play in every respect." It is performed "within a playground that is literally 'staked out"” since a sacred space functions as a "temporarily real world of its own." Both sacred play (as ritual) and ordinary play (as game), then, involve entry into a "temporarily real world" in a space "expressly hedged off for it” (14). Both involve the sense of entering into a controlled space, where play is shaped by possibilities determined by rules, comforting in its ordered nature. Sacred space, then, is a site at which play happens.

Of course, games have long had the ability to simplify real life events by placing them into idealized gaming spaces. Elliot Avedon and Brian Sutton-Smith surmise that board games have their origins in military planning, since "board-games, from the rudest up to chess, are so generally of the nature of kriegspiel, or war-game, the men marching on the field to unite their forces or capture their enemies, that this notion of mimic war may have been the very key to their invention” (73). Whether the desire to take over space via warfare was the original intention of board games or not, games are also very closely affiliated in history with religion and with the sanctification of territory. In the Hopi tribes of Arizona, for example, Stewart Culin identifies a ball game that is also a race, an event that itself symbolically functions as "a magical rite to secure fields within its circuit against sandstorms" (62). Clearly, the ritualized circumscribing of space has a long and often religiously-motivated history.

Game theorist Alexander Galloway sees contemporary digital play as similarly characterized by a walling off from ordinary life to create temporary ritualized spaces of experience. Galloway calls gaming "a ritualistic dromenon of players transported to the imaginary place of game-play, and acted out in the form of diegetic operator act” (37). ${ }^{2}$ Religion and game play both offer to ritually transport practitioners into an ideal space that offers a sense of purpose and meaning defined by pre-set rules. In ritual, play is seen in the interstices between prescribed activities, wherein the performer's choices emerge. Similarly, in games, play creates what Salen and Zimmerman call a "space of possibility" afforded a player to explore the world of the game and to make choices within it:

The space of possibility of a game is a plane stretched between two anchorage points: the beginning and the end of the game. The players journey from one end to another, making their way from start to finish. In a well-designed game that supports meaningful play, this journey between points should be taut and efficient, with every element contributing directly or indirectly to the larger experience. (258)

One can easily see how ritual, especially religious ritual, does similar kinds of work, creating a string of predetermined actions within predetermined space, creating meaning through the tension between what one can do and what one ought not do. Ritual theorist Roy Rappaport describes rituals as having "liturgical orders" or "invariant sequences of formal acts and utterances repeated in specified 
contexts” (429). Stanley Tambiah also points to the formal structure of many ritual experiences, describing ritual as "constituted of patterned and ordered sequences of words and acts, often expressed in multiple media, whose content and arrangement are characterized in varying degree by formality (conventionality), stereotypy (rigidity), condensation (fusion), and redundancy (repetition)” (497). Frits Staal claims that in ritual activity, "the rules count, but not the result" whereas "in ordinary activity it is the other way around... What is essential in the [ritual] ceremony is the precise and faultless execution, in accordance with rules, of numerous rites and recitations" (487). Despite the amount of "play" that might be evoked, rituals often include rather rigid rules, and like games develop meaning for the performer through engagement with those rules.

Games, then, can work in ways that remarkably resemble rituals-down to the emphasis on a kind of rigid repetition requiring "faultless execution" of predetermined gestures and behaviors. Games also closely link ritual experience and circumscribed space. Game theorists Katie Salen and Eric Zimmerman describe games as taking place in a carefully demarcated other space, arguing that "the frame of a game is what communicates that those contained within it are 'playing' and that the space of play is separate in some way from that of the real world” (94). However, just as ritual theorists argue about the fluid give-and-take between the ritualized and the real, Salen and Zimmerman similarly urge that we should not assume that gaming spaces have no bearing on ordinary life. Far from being insulated from the real world, when we interact with games "as culture," we find that "the magic circle is not an impermeable curtain but is instead a border that can be crossed." That is to say, games are "not isolated from their environment, but are intrinsically part of it, participating in the ebb and flow of ideas and values that make up a larger cultural setting." The effects may be explicit or implicit, but games exist in real life contexts, and are played by real people, who are shaped by the experiences. When engaged with the magic circle of game play "cultural meanings ripple outward from the game to interact with numerous cultural contexts" (572). Something real happens when we play games and when we engage in rituals.

Both games and religion, then, create circumscribed other-spaces in which meaningful choices are made, indeed, in which meaning is made through choices. Ritual and space are linked in both. The magic circle, the religious ritual, and the sacred space are all kin concepts, equally concerned with a space set apart from ordinary life in which fixed rules adhere, promising predictability and creating meaning. Play thus depends upon the notion of fixedness, and exists in the agitation of interpretation, transformation, re-creation that is possible because a more solid standard prevails in the form of rules, a fixed story, or a preconceived environment. Gamer theory and ritual theory meet at precisely this point, evoking comparisons between the demarcated space of play and the arena of ritual performance, inviting difficult questions about the relationship between real space and imagined space, between religion and games, belief and action. The notion of belief then becomes a crucial element in examining the perspective of players as they navigate in and out of imagined other worlds and spaces. 


\section{Making Belief}

If a "magic circle" is a map, a set of rules, and a template for an imagined world, then a ritual space is also a kind of magic circle that is intended to reflect its radiance onto the real world writ large. Belief is the means by which this mapping is made effective. The "magic circle" of the sacrament of communion, for example, is intended to generate its efficacy from the altar outward as a result of belief, encompassing the space of the whole world, where the "rules" of that transaction are then presumed to still hold. Belief is deeply implicated in adhering to the set of rules that define a magic circle in both rituals and in games. Rituals say to their performers: This is not a game. It's the real thing: what happens in this ritual space is real, authentic, and says something meaningful about how the world-the cosmosoperates. Games, on the other hand, seem to require belief of a different sort-a temporary adherence to the magic circle's rules and a mere performance of conviction. However, as I argue below, sometimes games can work as rituals, with as many meaning-making presumptions about mapping onto real life as a religious ritual. Indeed, we could argue that belief happens in the very assumption that what happens in a circumscribed space can and should spill over into everyday life.

The idea of belief as something that is "performed" is articulated persuasively by performance theorist Richard Schechner. In his discussion about the ritualized performance of belief, he proposes that we should distinguish between "making believe" and "making belief." For Schechner, "make believe" is an imaginative act that retains the boundaries between real and play, and is denoted by merely "pretending to believe." This category, then, would encompass the attitude embraced by most players of games, including videogames. We "make believe" when we choose to enter into temporary gaming spaces to abide by the rules circumscribed therein. Indeed, with "make believe," the rules of such spaces are to be abided by only within the game's space and time. A game, in this case, is "just" a game.

By contrast, "make belief" involves an intentional blurring of these boundaries in that performers are "enacting the effects they want the receivers of their performances to accept "for real"” (Performance Studies 35). "Make belief," then, sounds more like the way religion tends to work. Religious belief is performative; it enacts that which it presumes to depict, often through prescribed rituals. Schechner elsewhere looks at the role of art in religion and "other belief systems" to propose that in "make belief" people construct belief when they "make what isn't there, combine elements from fantasy, actualize situations that occur only as art or performance. These actualizations in the service of social organization, thought, ritual, or rebellious anti-structure contain, transmit, and (dare I say it?) create the very circumstances they purport to depict" (Performance Theory 220-21). Put bluntly, the difference here is between belief as religious conviction and suspension of disbelief as the commitment to gaming worlds. Bernard Suits calls suspension of disbelief in gaming situations the "lusory attitude," and says that it explains the "curious state of affairs wherein one adopts rules which require one to employ worse rather than better means for reaching an end" (38). When one plays a game, one 
suspends disbelief by committing to the rules of the game, by entering its world and ascribing to its rules. If this is a form of belief, it is presumed to be temporary and contingent.

Belief and suspension of disbelief, however, both involve choice, and both manifest in forms of play and ritual. Both too often are expressed in relationship to circumscribed spaces. But "make belief” seems to demand more of us than suspension of disbelief; it requires that we see the whole world as a game, as the space of play. Furthermore, "make belief" seems to require assent to one set of rules only, and this in turn may require us to identify winners and losers, to expect everyone to play by the same rules. Religious belief, as a kind of "make belief," requires that its magic circle spill over to encompass all of life. Here is where the game of religion can become ugly - when the purpose of play is to convince everyone else that your game is the only one worth playing, and those who won't adhere to your rules are rejected. But under certain circumstances gamers too can commit so deeply to the worlds they enter into that the rules of the game bleed over into real life, urging some to see the world in simplistic us-versus-them modalities. ${ }^{3}$ Gamers too can practice "make belief."

The problem, then, is that the categories of "make believe" and "make belief" too easily collapse into one another. It's impossible to externally determine the authenticity of any personal belief that involves imagined space and ritualized performance, whether it is explicitly religious or not. The rules of belief can shape gaming environments as readily as religious ones can shape social environments in real life. And the suspension of disbelief is differentiated from "make belief" only by the presumption of imagination by those who "make believe" and the presumption of authenticity on the part of those who "make belief." The transition from "make believe" to "make belief" can be seen in a popular new form of gameplay, the ARG (alternate reality game). Also known as "pervasive play," this new mode of "make belief" invites the imprint of preconceived gaming rules onto reality, working much like a religion in its re-enchanting of everyday life with the seductive promise of discoverable purpose.

\section{This Is Not a Game}

One of the means by which we can observe the overlap between belief in games and belief in ritual is by looking at some of the emerging new modes of game play. Jane McGonigal defines "pervasive play" as forms of "mixed reality” games that use mobile or embedded digital technology to "create virtual playing fields in everyday spaces" (1). She identifies "immersive games" as those that additionally employ a "this is not a game” (TINAG) rhetoric. Such games "do everything in their power to erase game boundaries - physical, temporal and social—and to obscure the metacommunications that might otherwise announce, 'This is play'” (2). In other words, such games intentionally spill over from the circumscribed space of the game and into real life, mapping order onto it, lighting the world up with a sense of possibility that works much like religious awe. This spillover can happen through clues for the game that are shared by real life actors, phone calls made to player's cell phones, and 
through live group play that intersects with online goals. Belief is reinforced via the game's rules, marking it as functionally no different from a ritual in terms of shaped behaviors intersecting with the performance of belief. Indeed, pervasive play invites the same kind of enchantment of the world that would invite someone of faith to see miracles at work in the world, since in an immersive form of pervasive play, anything in one's environment might be part of the game, intended to relay a message or clue to the player.

"Belief" is exhibited in buying into the game, which involves committing to seeing the real world as necessarily filled with purpose and shaped by the rules of game play. Game becomes ritual, shedding the radiance of the magic circle onto the space of ordinary life, which itself is embraced within that circle of play. Sacred space becomes indistinguishable from life itself, which is made magical, charged with imagination by the ever-present possibility of meaning. Anything, anywhere might be part of the game, arranged just so by the game designers for our keen-eyed discovery. It's hard not to see in this kind of gaming the same impulse to belief that inspires hardcore religious folk to spot Jesus in a patch of ivy or the name of Allah in a fried egg. Religion, perhaps, can be viewed as the world's longest running form of pervasive play.

As if anticipating the dangerous implications of locating authentic belief in an environment of play, McGonigal proposes that "instead of focusing on the risks of real belief" in pervasive play we should ask questions like: "What are the specific pleasures and payoffs for gamers of feigned belief in a play setting?" and "How do these practices of performed belief influence players in their everyday, non-game lives?" Using qualifying terms like "feigned" and "performed," McGonigal is arguing that the magic circle remains intact as exhibited in the willful performance of belief on the part of the player. But at the same time she is arguing that the magic circle is permeable in its ability to shape other aspects of life beyond game play. Can players really simply choose how much of the game's argument spills over into real life just by remaining aware that they are playing a game? McGonigal thinks so. Players, she proposes, willfully choose to see the world as infused by the game's rules, and can tell when play should be put aside for other things. Games aren't real, she argues, but they can have real effects, making us stronger, braver, or more skilled. Belief is bracketed, qualified, circumscribed, denied. And yet, the activity of spillover from the circumscribed space of game play onto real life is observable, and belief seems a required component.

Furthermore, McGonigal doesn't offer us any means for clearly differentiating between the "performance of belief" and belief itself, apart from gesturing toward the player's innate sense that he or she knows that belief is merely performed. But belief always seems to be a performance in whatever context it appears, manifesting as the willingness to abide within a given worldview, even if temporarily, and to follow the rules of that world. Furthermore, the performance of belief cannot be distinguished from belief itself by just saying the former is confined to a magic circle of play and the latter is linked to religious practice and ritual, since games do in fact always spill over into real life in some form or another, even if they are not forms of pervasive play. In distinction from McGonigal, I argue that the 
magic circle (the "sacred space" of a game) is permeable just like any other mode of cultural practice. Belief is to be defined as performed investment in the rules and values of a given "magic circle," and it is visible in the ways that people allow the "magic circle" to spill over into everyday life. In every case, the give and take between space of play and real life is fluid, with games shaping real life experience. "Make believe” easily slips into “make belief” when we aren’t paying attention.

\section{Games and Frames}

The ritual and sacred qualities of circumscribed spaces also find an analog in how game theorists talk about games and frames. Indeed, this analogy gestures against the insularity of gaming that McGonigal insists upon by showing that all games, like all rituals, are human constructs that are interactive with the larger culture in which they reside. Gamer theorists Salen and Zimmerman acknowledge that games are not always impervious "magic circles," and use the language of "frames" to talk about how games intersect with real life, proposing that "the wider our cultural frame grows in defining games as culture, the more their artificiality begins to unravel” (572). Because games are played by players - that is, by living human beings, games cannot be seamless spaces completely separate from real life. They are part of culture and can, at times, profoundly shape it. Gamer theorists Jon Dovey and Helen Kennedy agree, proposing that for games, the "magic circle" defines a separate space for play, but "it is not a utopian space, a nowhere-it still exists in the context of social time and material space" (29). Like sacred spaces, games exist in real and sometimes ideologically charged environments.

Rituals, too, are deeply interactive, as contemporary ritual theorists understand. Accordingly, the term "ritual" is increasingly being replaced by the term "performance" or "ritualization" as a means of emphasizing the interactivity, the procedurality, involved in a ritual. As Rappaport notes, "performance as well as formality is necessary for ritual” (428). Even those theorists like Staal who deny the communicative function of ritual altogether do generally concede that ritual is something that people do: "Ritual is primarily activity" and "the important thing is what you do, not what you think, believe, or say" (485). Seen in this way, ritual is intensely "interactive," characterized by what Catherine Bell describes as "interaction of the body with a structured environment." Focusing on the individual's negotiation with a ritual structure, Bell suggests that "ritual mastery" is "a corrective to the habit of thinking about ritual as an existing entity of some sort” (107). Ritual is a process, she argues, tied up deeply with other social processes that are encountered, assessed, and either appropriated or rejected by individuals. What is most important about ritual, she says, "is not what it says or symbolizes, but that first and foremost it does things” (111). Ritual is always a performance, always engaged in by real people in real lived environments. Both games and rituals, then, can be understood to be circumscribed, scripted experiences that are shaped by, and spill back over, into their spatial and social contexts. 
Such an argument reveals the red herring in contemporary debates about whether or not video games “cause” violent behavior. Video games do not directly cause violent behavior, nor are they utterly benign. Instead, if we view video games as having the ability to work like rituals, as entities functioning like sacred spaces, then it becomes obvious that they have the power to profoundly shape our attitudes, without directly causing or predetermining any particular behavior. Like all symbolic systems, video games present us with a visual and performative language, and through their procedural rhetoric, they encourage certain views about the world. Games don't force us to do anything, but they do shape our values, just like rituals do.

As ideologically-charged circumscribed symbolic spaces, video games, especially violent war games, can be compared to the "sacred spaces" of battleground memorials. Edward Linenthal argues that battle reenactment is "another form of veneration" in the sense of civil or patriotic religion, in that reenactors "seek imaginative entry into the heroic past, re-creating the total environment of the time of battle and thus paying meticulous attention to the authenticity of the clothes they wear and the food they eat." Such reenactments circumscribe history, telling us how to make sense of events of war, and even presenting the "dangerous illusion" that war is "glamorous" (5). War-infused video games like the Call of Duty franchise, Gears of War series, and the Medal of Honor series of games similarly promote the glory of war by defining it in terms of strict notions of victory and defeat, us-versusthem-whether they are set in recognizable earthly locations or in imagined earthlike planets. The website for Medal of Honor describes the mapping abilities of the game's design. Medal of Honor: Warfighter "gives players the ability to be in real world events" and "lets you experience the action as it might have taken place in the field." With a game story that was "written by actual Tier 1 Operators," the game invites players to "step into the boots of these warfighters and apply unique skill sets to track down a real global threat, in real international locations, sponsored by real enemies." The digital space of the game is meant to be read as mapping onto the real life space depicted in it, since "It doesn't get any more authentic than Medal of Honor: Warfighter."

Jesper Juul says that most games depend upon such mapping techniques, requiring at least one instance in which "the player performs some act, such as moving a piece on a board or pressing a key on a keyboard, that is projected as having a specific meaning in the game world. The moment of mapping is one that has a basic sense of happening now, when you play” (134). A real-life physical action such as pressing a key or using a joystick "immediately affects the world inside the game," such that the game can actually be seen as a "parallel world, happening in real time” (133). In 2007, this kind of performative mapping had serious effects when the Anglican Church objected to a violent shootout that takes place in a virtual replica of Manchester Cathedral, within the video game Resistance: Fall of Man. Even though the shootout involved the destruction of aliens in an imagined alternate history, the Church still argued that the use of a well-known sacred space within the violent context of the game rendered it symbolically damaging. The mashing of buttons, in this case, was seen as constituting a form of "virtual desecration" since it 
resulted in visual destruction of the Cathedral's environs. ${ }^{4}$ In the case of war-based video games depicting real-life events, this performative mapping typically serves as a simplification of real events according to the internal logic of the game itself. A virtual form of the sacralization of battle, these video games perform functions similar to battle re-enactments by distilling the notion of war into a simple urge for victory. In such cases, storytelling is ideological and performative. When video games involve the violent destruction of real life sacred space, as in the case of Resistance: Fall of Man, the symbolic stakes are even higher.

The question we should be asking then is not whether video games can shape us as ideological "spaces" with performative power-but rather how we are shaped by them. We should, of course, be hesitant to propose that all games have deep cultural power. For some, the magic circle remains mostly intact, affecting us lightly or in harmless ways. This is especially true for extremely abstract games like tic-tac-toe or chess, and true for many of the most creative modes of otherworldly fantasy game play. However, all games have some effect on our lives, and even for those videogames that seem to have no intrinsic affiliation with day-to-day reality, the spillover can be profound: product display, comic conventions, LARPing (live action role play), and even just local fandom can introduce elements of game play into the space of real life in complex negotiation. The magic circle is permeable, even if the spillover takes many different forms. This is as obvious as the costumes that players wear at conventions and the swag that devoted fans will buy about their favorite movie or videogame. We already knew that religious rituals can shape worldviews, but it is now obvious that games have this quality too. Both games and religious rituals are interactive forms of play, agitating against a firmer ground of perspectives embedded into the magic circle of the given activity. We move now to a focus on the kinds of activities encouraged in violent video games, and to another key concept, procedural rhetoric.

\section{Procedural Rhetoric}

Game theorist Ian Bogost coined the term procedural rhetoric to refer to "the practice of persuading through processes in general and computational processes in particular." Procedural rhetoric can help us understand both production and reception of videogames, since procedural rhetoric is "a technique for making arguments with computational systems and for unpacking computational arguments others have created" (3). Procedural rhetoric invites inquiry into "the way things work: the methods, techniques, and logics that drive the operation of systems” (9). Computerized processes argue things by asking us to do things, even if only symbolically. Machines respond to us, creating what Galloway calls "grammars of action" that, like rituals, limit our choices in predetermined ways (4). As Galloway explains, "Acts of configuration are a rendering of life" (16). Put in familiar terms, virtual spaces always function as "magic circles," microcosms of meaning that project their worldview onto real life, whether or not we consciously recognize these processes at work. The programming of virtual spaces by design implies purpose on the part of the designer, and the limitation and shaping of experience. 
Lawrence Lessig warns that with any digital medium, “code embeds values. It enables, or not, certain control . . . to the end of whatever sovereign does the coding" (114). Indeed, choices are so transcribed that we might, with Torben Grodal, describe most video games simply as "collections of linear stories" in which the options are "only virtual” (146). Each game world is based on a map or "system of multiple linear routes" through virtual space and virtual interactions or choices (147). As Arthur Asa Berger notes, “the player's feeling that he or she is in control is only an illusion. Every choice, and its attendant consequences, has already been placed in the story by the programmers, writers, and artists who created the game” (191). Both games and rituals create imagined spaces in which rules adhere that affect our lives, even when the game or ritual has ended. Sometimes these worldviews are banal and innocent, but other times they can shape our perspectives in damaging ways.

Procedural rhetoric, of course, applies to more than just computation. Many cultural systems, religion and its rituals included, exhibit persuasive processes. Gerardus Van der Leeuw's classic analysis of religion, Religion in Essence and Manifestation, explores the positioning of sacred space as what Chidester and Linenthal deem a "political act," with intentional "positioning" that typically involves "selection, orientation, limitation, or conquest" such that "every establishment of sacred space [is] a conquest of space" (7-8). Possession or control of sacred spaces can be seen as a kind of "procedural rhetoric" engineered by believers to make a particular ideological point about the world, and sometimes even the cosmos at large. As in video games that require symbolic elimination of enemies, the "politics of exclusion might be an integral part of the making of sacred space" (8). Sacred spaces evoke and are shaped by preconceived procedural rhetorics, manifest in transactions of use, abuse, transformation, negotiation, and presentation, and in arguments about who belongs and who does not. We turn now to look at some examples of games that integrate many of the key principles we have considered so far. In these games, we can see explicit procedural rhetorics functioning like rituals of exclusion, integrating the performance of belief through mapping circumscribed gaming environments onto real life situations.

\section{Mapping Real-Life Spaces}

Games, as we have already seen, always exist in context; the space of the game is always related to the space of real life. Our job is to think about how this is the case, and to be critical of those games that too readily simplify a complex globalizing culture, and that accordingly encourage players to embrace a naïve procedural rhetoric about real life. As Friedland and Hecht point out, violence "is a form of communication," and symbolic violence, especially in sacred spaces, "is an adjunct to material violence," used by one group of people to "mobilize their communities" against another one, and to "make their definition of reality the dominant one, to demonstrate the ultimate powerlessness of the other, and to redefine the other as radically alien, as profane." Sacred space is an especially potent site for symbolic violence, since "[b]y profaning the other's sacred place you make the other profane, 
an alien with no claim to possession of that space” (56). So it may matter little if the symbolic violence happens on real ground or in virtual space; the damage done may be equally palpable. Several recent video games reveal how game space can function as set apart or "sacred" space by presenting an idealized view of the world marking out who doesn't "belong” and mapping a gaming reality onto real life via an ideological discourse of divisive play.

In August of 2007, actor Stephen Baldwin, along with his Christian evangelical entertainment troupe Operation Straight Up (OSU), sponsored a movement to deliver copies of Left Behind: Eternal Forces inside care packages for U.S. troops in Iraq, a move presumably approved by the U. S. Department of Defense. OSU president Jonathan Sprinks said of their activities in Iraq: "We feel the forces of heaven have encouraged us to perform multiple crusades that will sweep through this war-torn region” (Schechter). Such a claim is especially troubling due to complaints by Muslim and Jewish groups that the game depicts these religious groups negatively, with some characters portrayed as ultimately unredeemable and therefore simply as enemies to be destroyed in its apocalyptic scenario. The space of the game exhibits a damaging procedural rhetoric that is meant to translate onto real life in the form of prescribed negative attitudes about those who believe differently. When the plan to distribute the game to soldiers was exposed, the resulting public outcry caused the Department of Defense to withdraw support for delivery of the game, but other games with less obvious religious affiliations are still played by soldiers, with potentially damaging procedural arguments for how to deal with difference.

It is not just evangelical Christians who create games with the intent to map a game's procedural rhetoric onto the space of real life. Vit Sisler describes the immensely rising popularity of cyber cafes in the wealthy Gulf states of the Middle East. The cafes are "equipped with networked computers and occupied till late at night by a predominantly young, male audience-playing games, commenting on how others play, and socializing around these activities.” The playing of these games, says Sisler, is not passive but "rather it is a dynamic interaction between production and fulfillment of expectations, meanings, and messages.” In 2003, the Hezbollah Central Internet Bureau released Special Force, a game designed to represent the Hezbollah missions during the Israeli invasion of southern Lebanon in the early 1980s. As author Helga Tawil Souri argues, "the driving force behind children going in droves to computer centers was not to escape the violence on the streets but to participate in the violence on digital screen" (36). In the game, players act as Lebanese fighters from the real-life mission, and practice their "shooting skills" while aiming at Israeli prime minister Ariel Sharon and other Israeli leaders (35). Souri observes that "[a]lthough [such] games are based on actual history, their lure for Arab gamers has been the ability to turn the tables on Israeli power over Palestinians and have the upper hand in the resistance without any real-life repercussions" (538). The popularity of the games, then, has something to do with the real-life wish to map the games' violent procedural rhetoric onto real life situations, to "win" and to oust the "losers." 
Media theorist Mark J. P. Wolf explains that in violent shooting games, "if the player-character does not attack or kill the other characters, he is killed and the game ends badly." The game's procedures and rules work to "guide a player into a particular way of thinking" in real life (109). The "this is not a game" principle is particularly powerful here; games are no longer "just” games but have become powerful rituals of imagined performance. They have become sacred, "set apart" spaces, symbolic arenas of religious polarization informed by a mutually reinforcing assumption of providential design within the game and in real life. As Bell puts it, "ritualization is the way to construct power relations when the power is claimed to be from God, not from military might or economic superiority; it is also the way for people to experience a vision of a community order that is personally empowering” (116). Games functioning as rituals make us feel stronger and more powerful, even when real life suggests otherwise.

Some U.S. military officials seem to have agreed with the potency of video games as ritualized shapers of behavior and perspective. Lieutenant Colonel Scott Sutton, director of the technology division at Quantico Marine Base, told The Washington Post that many young recruits are video game players and thus "probably feel less inhibited, down in their primal level, pointing their weapons at somebody." A combat engineer also interviewed by the Post compared shooting at insurgents in Iraq to playing Halo, a very popular futuristic fighting game: "It felt like I was in a big video game. It didn't even faze me, shooting back. It was just natural instinct. Boom! Boom! Boom! Boom!” Even though Halo depicts a fantastic, otherworldly space in which fighting against aliens occurs, soldiers can easily recognize the dualistic procedural rhetoric of the game, and can translate it directly to the battlefield, letting Iraqis take the place of the aliens: "The insurgents were firing from the other side of the bridge... We called in a helicopter for an airstrike... I couldn't believe I was seeing this. It was like Halo. It didn't even seem real, but it was real.” Another soldier expressed trepidation the first time he fired his gun, an M249 squad automatic weapon but acquired confidence upon remembering what it felt like to play violent video games: "I was scared. I had never shot my gun before at an actual person. But once I pulled the trigger, that was it, I never hesitated... All I saw was the street where the RPG [rocket-propelled grenade] came from, and I just fired in that direction, maybe 20 rounds at most, and it felt like I was playing Ghost Recon at home" (Vargas). These are effective rituals, indeed.

Such simplistic modes of us-versus-them are particularly common in war-based video games, where a game's procedural rhetoric can be viewed as identical to the procedural rhetoric mapped onto real-life spaces of war. There is no need, in such worldviews, to encounter an enemy as a person-he or she is simply an obstacle to be overcome. One soldier interviewed by Jose Vargas claimed that he fully understood that video games are different from real war, but explained how games can prepare you for battle anyway: "Of course, [war is] not a game. The feel of the actual weapon was more of an adrenaline rush than the feel of the controller... But you're practically doing the same thing: trying to kill the other person. The goal is the same. That's the similarity. The goal is to survive." As Friedland and Hecht observe of sacred space, symbolic violence is "a way to mobilize intense opposition, 
to polarize the situation using a very few resources” (56). Because virtual sacred space has the same symbolic power for some as real life sacred space, the effect of symbolic violence can be just as powerful in fomenting enmity.

Stereotyped digital representations only increase the binary effect. Sisler critiques a number of games in which Muslims are depicted with a distorted lens, arguing that such games "exhibit very similar stereotyping and schematizations to those that are already known from other media." Citing Prince of Persia, The Magic of Scheherazade, and Arabian Nights, Sisler argues that "these games typically feature characters like Bedouins, caliphs, djinns and belly dancers; navigate players through bazaars, harems and the desert; and the story often contains plots like saving kidnapped woman or assassinating an evil vizier." Such games, says Sisler "flatten out the diverse ethnic and religious identities of the Islamic world and reconstruct them into a few schematized characters" (qtd. in Haenni). By repeating the same troubling procedural rhetoric of encounter, these games work like powerful rituals of exclusion.

Such games can also work as a sinister kind of "sacred space.” As Chidester and Linenthal note, sacred space is far from neutral, but is rather "a means for grounding classifications and orientations in reality, giving particular force to the meaningful focus gained through these aspects of a worldview." Functioning as "significant space," sacred locations "focus a classification of persons, carving out a place for a human identity that can be distinguished from superhuman persons, perhaps to be worshiped, and those classified as subhuman who can be excluded, manipulated, dominated, degraded, or sacrificed" (12). Stereotypes abound on both sides in these games; American games present skewed portraits of Muslims and Arabs, and games produced in Muslim and Arab countries present distorted views of Americans. ${ }^{5}$ By mapping the game's space on top of real life space and integrating a divisive procedural rhetoric, such games suggest we should see real life spaces as following the same set of damning rules.

\section{Digital Dualism}

As "highly charged sites," sacred spaces invite “contested negotiations over the ownership of symbolic capital (or symbolic real estate) that signifies power relations" (Dyer-Witheford and de Peuter 16). Sacred places, say Chidester and Linenthal, "are arenas in which power relations...between insiders and outsiders, rulers and subjects, elders and juniors, males and females, and so on, can be adjudicated" (16). Violent war-based video games come to function together in this way, as a kind of repetitive sinister ritual of digital dualism in crafted "sacred space." The simplified spaces of these games offer a means of dealing with the complexity of difference through hatred and killing, a reliable but heartless algorithm.

Through the sacralization of a fixed procedural rhetoric (a ritual experience) within an idealized space of play, such games habituate us to the idea of war. This is not to say that we should engage in the kind of over-generalized and naïve claims of people like Jack Thompson and David Grossman who argue that violent video 
games directly teach players to kill. ${ }^{6}$ Rather, violent war-themed video games are part of what Nick Dyer-Witheford and Grieg de Peuter dub "an ensemble of practices aimed at disinhibiting, disciplining, and directing deadly aggression, ferociously etching direct lines from simulation to actuality." They function as rituals of desensitization and inoculations against complexity. Cultural "militarization" of life makes war seem normal, resulting in narrow-minded perspectives about how to deal with political and religious difference such that: "Hatred toward an officially designated enemy, triumph in his death, or at least indifference toward its necessity, vigilance against his wiles, acceptance of casualties in the course of struggle, uncritical loyalty for 'our side,' and so on, all become values promulgated across a wide social bandwidth" (117).

The ease with which war games present such dualistic views can be seen in the practice of "modding," the intentional and sometimes encouraged alteration of already written code in order to change the way that characters, buildings, and digital spaces look while leaving the procedural features of the previous game engine intact. One striking example of modding is Special Force 2, a Palestinian-produced game about the 2006 war in Lebanon between Israeli and Hezbollah. The game is based on the Far Cry engine, an American-produced PC war first-person shooter involving bloody, violent battle. Designers simply "modded" or "re-skinned" elements of the game like facial features, uniforms, and spatial settings for the conflicts, but retained the dualistic nature of the game's programming. In such cases, the imposition of a dualistic procedural rhetoric of hostility is simply transferred from one digital space to another, from one set of enemies to another. This work is similar to the kind of "symbolic labor" that goes into "choosing, setting aside, consecrating, venerating, protecting, defending, and redefining" real life sacred spaces, since both digital and real-life sacred spaces are imbued with rich symbolic power (Chidester and Linenthal 17). The symbolic activity of re-masking or "modding" as a mode of ideological discourse isn't so far removed from the kinds of debates that raged in the use of sacred space in such real life sites as the Temple Mount in Jerusalem and the Babri Mosque in Ayodha, India.

The magic circle of such games, exhibiting a predetermined dualistic worldview, is deliberately superimposed onto the space of real life, suggesting that either the game itself is not a game after all, or perhaps more problematically, that the space of real life, of war, is a game. "Make belief" is in effect here with the dualism of the game as the foundational premise. The preference to view reality in terms of winners and losers is not altogether surprising, since "most games have an end in which one or more players achieve victory” (Salen and Zimmerman 258). Games, as rituals, almost always require us to think in terms of us and them. The implications of such games for inhibiting interreligious and intercultural understanding are painfully obvious.

The digital medium itself is "biased toward the discrete," as Douglas Rushkoff warns us (52). It favors pre-designated choices over complexity, decision over comprehension: “Nothing in the real world is so very discrete, however. We can't even decide when life begins and ends, much less when a breath is complete or when the decay of a musical note's echo has truly ended... The digital realm is 
biased toward choice, because everything must be expressed in the terms of a discrete, yes-or-no, symbolic language. This, in turn, often forces choices on humans operating within the digital sphere" (55). As Rushkoff puts it, "All of the messy stuff in between yes and no, on and off, just doesn't travel down wires, through chips, or in packets” (56). And where the digital realm maps onto or over the physical world, these kinds of decisions can be forced onto situations where a both-and approach might be more appropriate, where complexity must be recognized, where the solution is not checking a box or answering a question but listening, weighing, agonizing, and perhaps relinquishing choice altogether at times in favor of open-ended conversation.

\section{The Case of Kuma War}

The insidious relationship between violent media representation, video game dualism, and real life events can be seen in startling clarity in the case of Amir Mirzaei Hekmati, an Iranian-American marine who is currently being held in prison by Iranian authorities, accused of spying and producing video-game based antiIranian propaganda. In this case, the us-versus-them framework is reflected in both American-produced Islamophobic media and in Iranian, anti-American media. The dialogue is expressed through a meta conversation taking place almost entirely within video games. The circumscribed "sacred space" of the game's world spilled over into real life, demanding a similar kind of dualism with heartbreaking consequences.

First released in 2004, Kuma War is a series of first- and third-person tactical strategy games, most of which are based on recent events in Iraq. Although Kuma War is not overtly religious, the game includes representations of mosques and sacred areas in its digital landscapes, and sometimes requires that players shoot enemies inside these sacred places. The game purports to "accurately reconstruct real-war events from the news"; however, the games cannot be perfect "reconstructions" due to their programmed, procedurally-fixed nature. Rather, they depict carefully selected and re-imagined locations, shaped by trajectories guided rigidly by the ideological worldview of their creators. The game's website includes over one hundred downloadable "missions," many of which feature U.S. military personnel as guests who describe the "real" situation on the ground. The means by which one "wins" the game is to violently occupy digital territory, which itself is modeled on real life spaces in Iraq. The urge to "win” at such reality-inducing games is rooted in a desire to overcome ambiguity through a resolution achieved by a game design that sorts players and events into "good" and "bad," into "winner" and "loser." Salen and Zimmerman argue that games are all about trying to achieve goals, which sustain players' interest, their "engagement," and their "desire”: "Without a clear goal, meaningful game play is not possible." Players want to know how close or far they are away from winning, since otherwise "the game collapses into a jumbled heap of ambiguity" (258). In the case of Kuma War, then, the "ambiguity" of real life is ported into the game, resolved, then exported as a violent plan of action. 
The Kuma War games thrive on a clearly defined procedural rhetoric of "good guys" versus "bad guys," laying this dualistic reality over real life spaces and events, encouraging players to see real history in this simplistic way. I explain elsewhere about Kuma War's dualistic depiction of the death of Muammar Qaddafi:

The desire to translate events like Qaddafi's and bin Laden's deaths into video games is also part of what we might call algorithmic sorting: the cultural attempt to simplify complex historical and social issues into patterns that we can recognize and make sense of. Typically, this is accomplished by vastly reducing the variables and historical contexts involved and effectively transforming lived events into games with predictable rules, defeatable "bad guys," and the hopeful celebration of an "epic win.” (Wagner, "Will a Video Game Make Sense of Qaddafi's Death?”)

The situation has become increasingly controversial after Hekmati's detainment. In early January 2012, the Iranian government sentenced Hekmati to death. According to Hekmati's “confession,” he worked several years for the Defense Advanced Research Projects Agency of the U.S., after which records say he admitted to engaging in violent video game design as a means of creating propaganda:

I was recruited by Kuma Games Company, a computer games company which received money from C.I.A. to design and make special films and computer games to change the public opinion's mindset in the Middle East and distribute them among Middle East residents free of charge. The goal of Kuma Games was to convince the people of the world and Iraq that what the U.S. does in Iraq and other countries is good and acceptable. (Mackey)

According to the confession, which is disputed, Hekmati helped to compose several missions for Kuma War, including a mission depicting the killing of Osama bin Laden, another detailing an Afghan air strike, and most recently, the mission about the death of Muammar Qaddafi. Admittedly, Hekmati's involvement is not entirely unlikely, as "overlaps between the military and the game industry have grown ubiquitous” in recent years (Dyer-Witheford and de Peuter 101). But he can hardly be held responsible for the dualistic worldview of the games, since this dynamic is built into all of the games since the company's inception.

However, the Kuma War controversy began long before Hekmati was arrested. In 2005, Kuma War released a mission called “Assault on Iran,” involving an imagined American military attack on the Nantanz uranium enrichment facility. The game was met with an Iranian "mission" of the same video game, intended to pick up the storyline where "Assault on Iran” left off. The 2007 Iranian game, "Special Operation 85: Hostage Rescue,” was produced by the Association of Islamic Unions 
of Students as a response to Kuma War's game mission. The Iranian game depicts the rescue of a husband-and-wife team of Iranian nuclear engineers. Gamers play as Iranian security forces on a mission that involves penetration of fortified locations in the attempt to free the Iranian engineers. To win the game, players kill U.S. and Israeli soldiers in Israel and capture secret information from them (Dareinim).

Not to be outdone, Kuma War responded with promises of a third installment, a videogame intended to pick up where the Iranian game left off. "Assault on Iran, Part 3: Payback in Iraq,” again portrays the nuclear scientists, but in the American game they are now depicted as defectors. According to a press release, Kuma War's third installment was intended "to bring to the foreground key issues at stake in the current nuclear standoff and create a game-powered forum for frank dialogue on the real-world conflict." Indeed, Kuma War's website describes "this kind of gamebased dialogue” with Iranian game-makers as "thrilling," and invites their Iranian counterparts to pick up again where they leave off in the game's meta-story. The problem, of course, is that all versions of the game, Iranian and American, depend upon an us-versus-them model, with story resolution in every case dependent upon violence. Furthermore, in all versions of the game, Iranian and American, the simplistic dualistic procedural rhetoric of the game is repeated with ritual intensity and mapped onto real-life events and spaces, suggesting in classic "this is not a game" form that real-life conflict can be reduced to simple algorithms of us-versus-them. All versions of the game, then, function as a sort of conversation about values, with the depicted spaces within the games functioning as contested ideological symbols, recursively transformed by successive game designers but all dualistic and all antagonistic, all urging "make belief” as a means to eliminate ambiguity.

Although the American and Iranian versions of the game utilized different storylines, both can be reduced to the same procedural rhetoric of us-versus-them with a ritualized argument for victory through violent defeat of one's enemies. The "sacred spaces" of the games reflect an identical ritualized mode of engagement in a "magic circle" with real life spillover, the goal of which is to punish those who are different. Iranian accusations against Hekmati were as dualistic as the games that they accused him of engineering. Hekmati could not be Iranian-American, and he could not have complex or divided loyalties. Hekmati's prosecutors decided, based on his work for an American gaming company, that he must be an enemy, and sentenced him to death for espionage. As of today, Hekmati is still in prison awaiting retrial. The Kuma War games, however, continue unabated.

\section{Conclusion}

We live in deeply wired spaces, so embedded with machines that we hardly notice them anymore. In the past forty years, they have transformed our lives and, as media theorist Alexander Galloway notes, they have "precipitated massive upheavals in the lives of individuals submitted to a process of retaining and deployment into a new economy mediated by machines and other informatic 
artifacts" (17). But technology is not neutral. It is embedded with all the ideological limitations of the programmers who created it, who decided what choices we would have and which ones would not be offered to us.

Religion and games have always relied upon some of the same modes of experience, namely the construction and circumscription of a "magic circle" or ritualized space in which fixed worldviews are rehearsed and rules of behavior are defined. Both too have situated these idealized experiences within permeable membranes, "magic circles" that exhibit give and take in a cultural and spatial context. Both religion and games depend heavily upon formative ritual-like experiences to aid in the construction of meaning. The "magic circle," as a key concept for thinking about circumscribed spaces, reveals profoundly the ways in which games and rituals both mark off arenas of "play." Both demarcate certain areas as "sacred" or set apart, and both have the ability to invite projection of the values of the circumscribed space onto everyday reality. The case studies here, especially the case of Hekmati, show that if we are not conscious about the values we instill in our gaming rituals and virtual "sacred spaces," the results can be heartrending. Furthermore, the dualistic perspectives embraced by opposing gaming communities can feed one another, reinforcing the apocalyptic mindset that identifies other human beings as only "friend" or "foe." Violent video games too easily invite "make belief” with antagonistic rules.

The popularity of video games today reveals profoundly that human beings are persistently religious - we just change the way we express our religious needs. Our deep fascination with all things digitized, with ordered programming available to us via our beloved devices, reveals a hunger for organization which itself betrays a bewilderment with bounty and a frequent retreat to easy dualisms. Sacred spaces, as sites for powerful ideological negotiation, can be found in digital spaces as well as material ones. We should, then, think very carefully about the games we play. Even if violent war-based games don't urge violence directly, they run the risk of sanitizing it by presenting it as the only meaningful method for bringing order in the face of disagreement. In our increasingly globalized and anxious world, we wish desperately for new rituals and experiences that allow us to map order onto seemingly chaotic real-life spaces. We want something to believe, and we want discoverable rules with manifest purpose. Games offer us just such comfort, but if the games we play the most are still the ones that dehumanize others, this order comes at a very high price indeed.

\section{Rachel Wagner}

Rachel Wagner is Associate Professor of Religion at Ithaca College in upstate New York. She has published extensively on the study of religion and popular culture, especially religion and virtual reality. Her book, Godwired: Religion, Ritual and Virtual Reality (Routledge, 2011), places religious studies theory in conversation with gamer theory to reveal the key concerns of wired culture as it engages with human-created, idealized, digitally crafted worlds. More recently, she has been working on the intersection of gaming, violence, and apocalypticism. She 
is Co-Chair of the American Academy of Religion's Religion, Film, and Visual Culture Group.

\section{Notes}

1 For more on cyberspace as a proxy for religious notions of infinity, see Margaret Wertheim, The Pearly Gates of Cyberspace: A History of Space from Dante to the Internet (New York: W. W. Norton \& Co.), 1999.

2 Following gamer theorist McKenzie Wark, I use the term "gamer theory” to distinguish the study of games (especially videogames) from the older and more mathematical "game theory."

3 For more on how digital culture contributes to us-versus-them perspectives, see Wagner, Rachel, "First Person Shooter Religion: Algorithmic Culture and InterReligious Encounter.” CrossCurrents, June (2012): 181-203.

4 For more on this case, see Rachel Wagner, Godwired: Religion, Ritual and Virtual Reality (Routledge, 2011), 172-176.

5 Material cited here on Islamic videogames draws on shared research conducted with Ithaca College student Ranu Nath.

6 See David Grossman, Stop Teaching Our Kids to Kill: A Call to Action Against TV, Movie and Video Game Violence. New York: Random House, 1999.

\section{Works Cited}

Avedon, Elliot M. and Brian Sutton-Smith, The Study of Games. New York: John Wiley and Sons, 1971. Print.

Bell, Catherine. Ritual Theory, Ritual Practice. New York: Oxford University Press, 1992. Print.

Berger, Arthur Asa. Media Analysis Techniques. Third edition. Thousand Oaks, CA: Sage, 2005. Print.

Bogost, Ian. Persuasive Games: The Expressive Power of Videogames. Cambridge, MA and London: The MIT Press, 2007. Print.

Brasher, Brenda. Give Me That Online Religion. Jossey-Bass, 2001. Print.

Chidester, David and Edward T. Linenthal. "Introduction.” American Sacred Space. David Chidester and Edward T. Linenthal, eds. Indiana University Press, 1995. 1-42. Print.

Culin, Stewart. “American Indian Games.” American Anthropologist 5.1 (1903): 58-64. Print.

Dareinim, Ali Ali Akbar. "Iran unveils 'Rescue the Nuke Scientist' game.” USA Today. 16 July 2007. Web.

Dovey, Jon, and Helen Kennedy. Game Cultures: Computer Games as New Media. New York: Open University Press, 2006. Print.

Dyer-Witheford, Nick and Greig de Peuter. Games of Empire: Global Capitalism and Video Games. Electronic Mediations Series, Volume 29. University of Minnesota Press, 2009. Print.

Eliade, Mircea. The Sacred and the Profane: The Nature of Religion. Trans. Willard Trask. New York: Harper \& Row, Harper Torchbooks, 1961. Print. 
Friedland, Roger and Richard D. Hecht. “The Politics of Sacred Place: Jerusalem's Temple Mount/al-haram al-sharif." Sacred Places and Profane Spaces: Essays in the Geographics of Judaism, Christianity, and Islam. Jamie Scott and Paul Simpson-Housley, eds. New York: Greenwood Press, 1991. 21-61. Print.

Galloway, Alexander. Gaming: Essays on Algorithmic Culture. Electronic Mediations Series, Vol. 18. Katherine Hayles, Mark Poster, and Samuel Weber, eds. University of Minnesota Press, 2006. Print.

Grodal, Torben. "Stories for Eye, Ear and Muscles: Video Games, Media, and Embodied Experiences.” The Video Game Theory Reader. Ed. Mark Wolf and Bernard Perron. New York: Routledge, 2003. 129-155. Print.

Haenni, Patrick. "Religion and Technology: Video Games in the Arab World and Beyond -Interview with Vit Sisler.” Religioscope. 12 February 2009. Web. 2 March 2013.

Hillis, Ken. "Modes of Digital Identification: Virtual Technologies and Webcam Cultures.” New Media, Old Media: A History and Theory Reader. Ed. WHK Chun and T Keenan. New York: Routledge, 2006. 347-358. Print.

Huizinga, Johan. Homo Ludens: A Study of the Play Element in Culture. London: Routledge \& Kegan Paul, 1949. Print.

Juul, Jesper. "Introduction to Game Time.” First Person: New Media as Story, Performance, and Game. Ed. Noah Wardrip-Fruin and Pat Harrigan. London, England and Cambridge, MA: The MIT Press, 2004. 131-142. Print.

Lessig, Lawrence. Code: And Other Laws of Cyberspace, Version 2.0. New York: Basic Books, 2006. Print.

Linethal, Edward Tabor. Sacred Ground: Americans and Their Battlefields. Second Edition. Urbana and Chicago: University of Illinois Press, 1993. Print.

Mackey, Robert. "Iran Calls Video Games Part of C.I.A. Plot.” Blogging the News with Robert Mackey. The New York Times. 9 January 2012. Web. 12 January 2013.

McGonigal, Jane. “A Real Little Game: The Performance of Belief in Pervasive Play,” Digital Games Research Association (DiGRA) “Level Up” Conference Proceedings, November 2003. Web. 8 January 2012.

Rappaport, Roy. “The Obvious Aspects of Ritual.” Readings in Ritual Studies. Ed. Ronald Grimes. Upper Saddle River, NJ: Prentice Hall, 1996. 427-440. Print.

Rushkoff, Douglas. Program or Be Programmed: Ten Commands for a Digital Age. New York: ORBooks, 2010. Print.

Salen, Katie and Eric Zimmerman. Rules of Play: Game Design Fundamentals. Cambridge MA and London, UK: The MIT Press, 2003. Print.

Schechner, Richard. Performance Studies: An Introduction. Routledge: New York and London, 2006. Print.

Schechner, Richard. Performance Theory. New York: Psychology Press, 1988. Print.

Schechter, Anna. "DoD Stops Plan to Send Christian Video Game to Troops in Iraq,” ABC News: The Blotter. 15 August 2007. Web. 22 March 2008.

Sisler, Vit. "Video Games, Video Clips, and Islam: New Media and the Communication of Values." Muslim Societies in the Age of Mass Consumption. Ed. Johanna Pink. Newcastle: Cambridge Scholars Publishing, 2009. 231-258. Print. 
Souri, Helga Tawil. "The Political Battlefield of Pro-Arab Video Games on Palestinian Screens.” Comparative Studies of South Asia, Africa, and the Middle East 27:3 (2007): 536-551.

Staal, Frits. "The Meaninglessness of Ritual." Readings in Ritual Studies. Ed. Ronald Grimes. Upper Saddle River, NJ: Prentice Hall, 1996. 483-494. Print.

Suits, Bernard. Grasshopper: Games, Life, and Utopia. Orchard Park, NY: Broadview Press, [1978] 2005. Print.

Tambiah, Stanley. "A Performative Approach to Ritual." Readings in Ritual Studies. Ed. Ronald Grimes. Upper Saddle River, NJ: Prentice Hall, 1996. 495510. Print.

Vargas, Jose Antonio. "Virtual Reality Prepares Soldiers for Real War." The Washington Post. 14 February 2006. Web. 14 December 2012.

Wagner, Rachel. “Will a Video Game Make Sense of Qaddafi’s Death?” Religion Dispatches. 23 October 2011. Web. 1 January 2013.

Wolf, Mark J. P. "Narrative in the Video Game.” The Medium of the Video Game. Ed. Mark J. P. Wolf. Austin: University of Texas Press, 2001. 93-111. Print. 

Iowa Journal of Cultural Studies 15 (Spring 2014)

Copyright (C) 2014 by The University of Iowa 